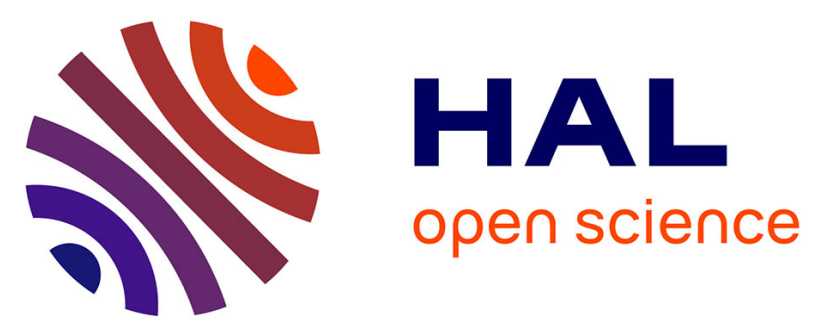

\title{
Impact of acoustic airflow nebulization on intrasinus drug deposition of a human plastinated nasal cast: New insights into the mechanisms involved \\ Marc Durand, Jérémie Pourchez, Gérald Aubert, Sandrine Le Guellec, Laurent Navarro, Valérie Forest, Philippe Rusch, Michèle Cottier
}

\section{To cite this version:}

Marc Durand, Jérémie Pourchez, Gérald Aubert, Sandrine Le Guellec, Laurent Navarro, et al.. Impact of acoustic airflow nebulization on intrasinus drug deposition of a human plastinated nasal cast: New insights into the mechanisms involved. International Journal of Pharmacy, 2011, 421 (1), pp.63-71. 10.1016/j.ijpharm.2011.09.023 . hal-00640705

\section{HAL Id: hal-00640705 https://hal.science/hal-00640705}

Submitted on 14 Nov 2011

HAL is a multi-disciplinary open access archive for the deposit and dissemination of scientific research documents, whether they are published or not. The documents may come from teaching and research institutions in France or abroad, or from public or private research centers.
L'archive ouverte pluridisciplinaire HAL, est destinée au dépôt et à la diffusion de documents scientifiques de niveau recherche, publiés ou non, émanant des établissements d'enseignement et de recherche français ou étrangers, des laboratoires publics ou privés. 


\section{Impact of Acoustic Airflow Nebulization on Intrasinus Drug Deposition of a Human Plastinated Nasal Cast: New Insights into the Mechanisms involved}

Marc DURAND ${ }^{1,2,3}$, Jérémie POURCHEZ ${ }^{2,3,4 *}$, Gérald AUBERT ${ }^{5}$, Sandrine LE GUELLEC

${ }^{6,7}$, Laurent NAVARRO ${ }^{3,4}$, Valérie FOREST ${ }_{2,3,5,8,9}^{2,3,4}$, Philippe RUSCH ${ }^{2,3,5,8,9}$, Michèle COTTIER

${ }^{1}$ Centre Hospitalier Emile Roux, F-43012, Le Puy en Velay, France

2 LINA, Laboratoire Interdisciplinaire d'étude des Nanoparticules Aérosolisées, EA 4624, F42023, Saint-Etienne, France

${ }^{3}$ SFR IFRESIS, F-42023, Saint-Etienne, France

${ }^{4}$ Ecole Nationale Supérieure des Mines de Saint-Etienne, Centre Ingénierie et Santé, F42023, Saint-Etienne, France

${ }^{5}$ CHU de Saint-Etienne, F-42055, Saint-Etienne, France

${ }^{6}$ DTF-Aerodrug, Faculté de médecine, F-37032, Tours, France

${ }^{7}$ INSERM-U618, Faculté de Médecine, F-37032, Tours, France

${ }^{8}$ Université Jean Monnet, Faculté de Médecine, F-42023, Saint-Etienne, France

${ }^{9}$ Université de Lyon, F-42023, Saint-Etienne, France

* Corresponding author: Tel: (+33) 4774201 80; Fax: (+33) 4774996 94;

E-mail address: pourchez@emse.fr 


\section{ABSTRACT}

2 Purpose: The impact of $100 \mathrm{Hertz}(\mathrm{Hz})$ acoustic frequency airflow on sinus drug deposition of aerosols was investigated using a human plastinated nasal cast. The influence of drug concentration and endonasal anatomical features on the sinus deposition enhanced by the 100 $\mathrm{Hz}$ acoustic airflow was also examined.

Methods: Plastinated models were anatomically, geometrically and aerodynamically validated (endoscopy, CT scans, acoustic rhinometry and rhinomanometry). Using the gentamicin as a marker, 286 experiments of aerosol deposition were performed. Changes of airborne particles metrology produced under different nebulization conditions $(100 \mathrm{~Hz}$ acoustic airflow and gentamicin concentration) were also examined.

Results: Aerodynamic and geometric investigations highlighted a global behaviour of plastinated models in perfect accordance with a nasal decongested healthy subject. The results of intrasinus drug deposition clearly demonstrated that the aerosols can penetrate into the maxillary sinuses. The $100 \mathrm{~Hz}$ acoustic airflow led to increase the deposition of drug into the maxillary sinuses by a factor 2 to 3 depending on the nebulization conditions. A differential intrasinus deposition of active substance depending on maxillary ostium anatomical features and drug concentration was emphasized.

Conclusion: The existence of a specific transport mechanism of penetration of nebulized particles delivered with acoustic airflow was proposed.

Keywords: acoustic airflow, aerosol therapy, drug deposition, plastination, maxillary sinus. 


\section{Introduction}

Rhinosinusitis is a significant and increasing health problem which results in a large financial burden on society (Fokkens et al., 2007). Due to the inflammation of the nasal mucosa or impaired mucociliary clearance, the blockage of sinus drainage leads to the creation of a favourable environment for sinusitis. Indeed, under these conditions bacteria and viruses cannot be removed by secretions drainage and may proliferate. Targeting delivery of nebulized antibiotics into the maxillary sinuses, the sites of infection, could improve clinical outcomes in patients with chronic rhinosinusitis. Thus, nasal drug delivery by nebulization is widely used in sinus disorders, because of its safety and convenience and due to its advantages as a painless therapy. Topical delivery of antimicrobial drugs for treatment of rhinosinusitis also brings intuitive advantages over systemic therapy. It minimizes the risk of systemic side effects, the development of antibiotic resistance in non targeted areas and allows a high topical drug concentration deposition with a minimal systemic adsorption.

However the nebulization conditions to facilitate penetration of aerosols into the sinus cavities are not well-established. The practice of aerosol therapy to treat rhinosinusitis has not been studied thoroughly, despite few works have shown clinical benefit (Vaughan et al., 2002). The main issue is that it remains very difficult to demonstrate an effective penetration of aerosolized drugs into paranasal sinuses which are poorly ventilated hollow cavities due to anatomical features. The maxillary sinuses communicate with the nasal fossa via narrow ducts: the maxillary ostia (about 1-5 $\mathrm{mm}$ in diameter; $10-15 \mathrm{~mm}$ in length) (Tarhan et al., 2005). However, some in vivo and in vitro studies have demonstrated that aerosolized particles can be deposited into paranasal sinuses but always at low concentrations (Hyo et al., 1989; Saijo et al., 2004; Hilton et al., 2008; Durand et al., 2001). These studies highlighted that the three main factors affecting the aerosol deposition into the maxillary sinuses are: the diameter/length of the maxillary ostium, the pressure/rate of the aerosol, and finally the airborne particle size. All things considered, a better understanding of ventilation and drug 
delivery to the maxillary sinuses is required to more accurately define the relevance of nasal drug delivery for treatment of rhinosinusitis despite the fact it is widely used by the clinicians. To enhance the penetration of nebulized particles into badly-ventilated areas (i.e. sinuses in healthy subject) or non-ventilated areas (i.e. sinuses in patients with sinus diseases), a pressure gradient generated by a acoustic airflow can be added to a usual jet nebulizer (Guillerm et al., 1959). Few literature citations consider the possible increase in value when an acoustic pressure wave is added to aerosol. Vecellio et al. recently demonstrated that, using a nasal sonic jet nebulizer loaded with 99mTc-DTPA in seven healthy male nonsmoking volunteers, aerosol deposition in the nasal cavity was $73 \pm 10 \%$ (\% of aerosol deposited into the airways) (Vecellio et al., 2011). They also highlighted that $5 \pm 2 \%$ of the total activity deposited into the nasal cavity was deposited in the maxillary sinuses. Moeller $e t$ al. showed in healthy volunteers a significant increased of ${ }^{81 \mathrm{~m}} \mathrm{Kr}$ gas ventilation of the paranasal sinuses using pulsating airflow (Moeller et al., 2008). These authors also showed that $6 \pm 2 \%$ of the total nose deposition reached the sinuses with pulsating aerosol delivery although less than $1 \%$ of this dose penetrated into the sinuses using a nasal pump spray (Moeller et al., 2010). Similarly, Maniscalco et al. demonstrated that a acoustic airflow increased the delivery of an aerosolised drug into the paranasal sinuses (Maniscalco et al., 2006). But the gain of intrasinus drug deposition brought by the use of acoustic airflow is neither well-established nor well-understood. Moreover, the underlying particle transport mechanism into the sinuses remains misunderstood.

Three main families of human nasal casts can be distinguished to study aerosol deposition: "pipe models" (Moeller et al., 2008; Maniscalco et al., 2006; Cakmak et al., 2003), plastic replicas (Schreck et al., 1993; Kelly et al., 2000) and models obtained from cadavers (Hilton et al., 2008). Unfortunately, the usual experimental casts present some drawbacks or specific restrictions: "pipe models" may not adequately mimic the anatomy of the human cavity, plastic replicas can suffer from a lack of thin anatomical details (such as the maxillary ostium 
morphology), and models from cadavers raise issues of time stability and biosecurity. Thus, a concept of human plastinated nasal cast without any tissue retraction phenomenon was proposed. Plastination permits the preservation of anatomical specimens in a physical state approaching that of the living condition. This technique was introduced by Dr. Gunther von Hagens in late 1970s (von Haggens, 1979). The plastination consists in replacing water and lipids in biological tissue by curable polymers. The advantages of plastinated nasal specimens are numerous: anatomical and aerodynamic behaviour close to in vivo, huge time-stability, water-washability, accessibility of the maxillary sinuses, easy handling, dry odourless, biologically safe and transportable without constraints.

This study aims at investigating the deposition of aerosols in the maxillary sinuses of a plastinated human nasal cast presenting dissimilar anatomical features of ostia, with and without acoustic airflow. The main purpose of this work was to highlight the influence of the $100 \mathrm{~Hz}$ acoustic frequency on the sinus drug deposition. To improve our understanding of the mechanisms involved, the gain of efficiency brought by the $100 \mathrm{~Hz}$ acoustic frequency was also evaluated depending on the gentamicin concentration initially introduced into the nebulizer and the maxillary ostium anatomical features. Thus, we successively performed anatomical and aerodynamic characterisations of the plastinated nasal cast, and studied the metrology of the aerosol (particle size and aerosol output rate) and the acoustic characterization of the $100 \mathrm{~Hz}$ acoustic frequency. Then we conducted 286 experiments of drug deposition into the maxillary sinuses using various nebulization conditions.

\section{Materials and methods}

\subsection{Elaboration of plastinated nasal model}

A specific plastination technique of cephalic extremities was developed in our laboratory over the last 10 years in order to obtain nasal casts without any tissue retraction and dedicated to functional studies (e.g. aerodynamic and aerosol deposition studies) (Durand et al., 2001; 
Croce et al., 2006). In this paper, we focus on a plastinated specimen (Figure 1) obtained from a deceased man who left his body to the Saint-Etienne Anatomy Laboratory. The plastination process consists in different successive steps: anatomical sampling, section, fixation, dissection, dehydration and degreasing, polymer forced impregnation in a vacuum, and then, curing and polymerization. All these steps were recently described in details in a form that a lab scientist could follow the procedure and generate an identical cast (Durand et al., 2011). Last, a specific lateral-paramedian section of the plastinated head was performed to open an exterior free access to the maxillary sinuses via the cheekbone (Figure 1). Maxillary volumes and aerodynamic behaviour of the model were nevertheless kept normal. This original opening allowed the collection and so the quantification of the active drug deposited into maxillary sinuses during aerosol studies. Technically, two removable plexiglass plates were used to hermetically close ("closed position" shown in Figure 2 step1), or not ("open position" shown in figure1B) the maxillary exterior opening during nebulization experiments and aerodynamic measures.

Legal and ethical principles were strictly respected during the elaboration of plastinated nasal model. Body donation to science authorizes in France a university to use a cadaver for teaching and research activities. The different steps of body donation to science are not governed by the French laws of bioethics, but by several legal and administrative texts. Before to use a cadaver obtained by donation, an authorization was obtained in which is clearly defines the usages for research and teaching. The legal's rules of anonymity were also complied and the donors were informed on the use of their donation. The respect of the donors and their families remains a key point of the administration ability to receive these donations. For all these reasons, the French Research Ethics committees do not have a legal's rules to approve the individual research on a cadaver. However the respect of good practices is frequently checked and valued. 
The objective of the characterization work was to evaluate the reliability of nasal cavity geometry and airflow resistance of the plastinated specimen compared to in vivo data. The methodologies used to anatomically, geometrically and aerodynamically characterize the plastinated nasal cast were recently described in details (Durand et al., 2011). A clinical anatomy study was firstly carried out using CT scans and endoscopy observations. These techniques were performed on the plastinated model in order to evaluate the preservation of mucosa in the cast (especially in the middle turbinate area) as well as to precisely define the geometrical features of the maxillary ostia. The geometry of nasal cavities was also characterized using acoustic rhinometry. This method is frequently used to determine in vivo the nasal cross-sectional areas through acoustics reflexion. Each nasal fossa of the plastinated specimen was separately examined leading to the characterization of the first six centimetres corresponding to the longitudinal area from the tip of the nostril to the middle meatus region. As a matter of fact, beyond the sinus ostium region, the acoustic rhinometry overestimates cross-sectional area and provide no quantitative data for sinus volume or ostium size (Tarhan et al., 2005).

Aerodynamic assessments were also performed using rhinomanometry providing an objective quantification of nasal airway resistance. Indeed, rhinomanometry is a well-established and reliable technique that measures nasal patency in terms of nasal airflow and resistance to airflow. The measured pressure-flow relationship reflects the functional status of the nasal airway. We examined separately the resistance of each nasal cavity (in "closed position") while the opposite nostril was occluded. Moreover, and for the first time, the serial resistance of both nasal cavity and ostium was also measured. For example, to measure the airflow resistance of ostium and nasal cavity on the right side, both nostrils were occluded, and right sinus cavity was kept in "open position" while the left sinus cavity in "closed position". These 
original and novel data provide some very important information on the impact of the ostium morphology on airflow resistance to enter the maxillary sinus cavity.

\subsection{Nebulization system}

The nebulization system, including an Atomisor NL11SN jet nebulizer associated with an $\mathrm{AOLH}^{\circledR}$ air source compressor (Diffusion Technique Française, DTF Medical, Saint-Etienne, France), can produced a "sonic aerosol" by adding a $100 \mathrm{~Hz}$ acoustic frequency during aerosol production. The acoustic frequency was continuously emitted since a vibrating capsule in the compressor $\left(\mathrm{AS}^{\circledR}\right.$ sonic generator, 110 Volts, DTF Medical, Saint-Etienne, France) and conducted through a $5 \mathrm{~mm}$ in width and $1-\mathrm{m}$ in length tube $(8.5 \mathrm{~mm}$ inside diameter) to the nebulizer outlet. Nebulizations were performed according to two options operating mode of the compressor/sonic generator: the classic mode without addition of the $100 \mathrm{~Hz}$ acoustic frequency, and the sonic mode with addition of the $100 \mathrm{~Hz}$ acoustic frequency. The nebulizer NL11SN was equiped with a nasal plug (C28 medium size, Diffusion Technique Française, DTF Medical, Saint-Etienne, France) purchased by the manufacturer and usually used in clinical practice. This nasal plug ensured the interface connection between nebulizer and the plastinated model's nostrils. Depending on the nebulization experiment, the NL11SN was filled either with $4 \mathrm{~mL}$ of a gentamicin solution, or with $4 \mathrm{~mL}$ of $\mathrm{NaF} 2.5 \%$ solution. The nebulizer operates at a flow rate of $8 \mathrm{~L} \cdot \mathrm{min}^{-1}$.

\subsection{Acoustic signal of the acoustic airflow}

The acoustic pressure waves added to the aerosol during its production by the sonic nebulizer NL11SN was characterized for a better understanding of its influence on aerosolized particles deposition in the maxillary sinuses. The acoustic signal coming out of the NL11SN has been characterized by a usual signal processing methodology, using a digital sound level meter (AZ Instrument) which measures the maximum acoustic pressure level. The measurements have 
been performed in free field (the distance from the walls was high enough to not influence the signal's behaviour and its frequency content) at exactly $1 \mathrm{~cm}$ of the output pipe. Besides the determination of the frequency components of the signal (fundamental amplitude and potential harmonics) a spectral analysis using the Fourier transform was used.

\subsection{Aerosol metrology}

The aim of the metrology study was to determine the impact of the $100 \mathrm{~Hz}$ acoustic frequency on the aerosol output and the particle size. All metrology experiments are summarized in Table 1. The output of gentamicin aerosol was measured simulating respiration with a sinusoidal pump and collecting aerosol on a filter. An absolute filter (Inhalation Filter Pad, Pari $\mathrm{GmbH}$, Germany) was interposed between the nebulizer system and the respiratory pump (Compas2, Pari GmbH, Germany) which was regulated according to standard NF EN 135441 (i.e. Sinus pattern - Tidal Volume of $500 \mathrm{~mL}$ - 15 breath/min - Inspiration:Expiration = 1:1). The equipments and fluids were stabilized at ambient conditions before use. The nebulizer system was connected to its associated compressor. Gentamicin was introduced into the nebulizer. The respiratory pump and compressor were turned on. Nebulization time was limited to 10 minutes. The amount of gentamicin collected by the filter was determined by a residual gravimetric method based on weighing dry filters (Vecellio et al., 2004). The output fraction was obtained by calculating the ratio between the amount of gentamicin collected on the filter and the amount of gentamicin initially introduced into the nebulizer.

Aerosol particle sizing was defined in terms of Mass Median Aerodynamic Diameter (MMAD). The MMAD was assessed using cascade impaction according to two complementary approaches using the NGI (Next Generation pharmaceutical Impactor, Copley Scientific, USA) and the ELPI (Electrical Low Pressure Impactor, Dekati Ltd, Finland). In cascade impactors, the aerosolized particles are impacted on different stages depending on their inertia related to their aerodynamic diameter. These devices allow simultaneous measure 
of the aerodynamic size and of the mass of active drug according to the different size ranges. The metrology was conducted either with sodium fluoride (NaF; $2.5 \% \mathrm{wt} ; 4 \mathrm{~mL}$ ) a chemical tracer recommended by European standard procedure (NF EN 13544-1), but also with gentamicin (40 and $80 \mathrm{mg} \cdot \mathrm{mL}^{-1} ; 4 \mathrm{~mL}$ ). Unlike the ELPI which was originally designed for industrial and environmental aerosols, the NGI was specifically designed for pharmaceutical aerosols and has been included in the British Pharmacopoeia as a test method for the measurement of aerodynamic particle size distribution (Marple et al., 2004). Thus the NGI was preferentially used for metrology experiments using gentamicin, because this cascade impactor was specifically designed to meet the requirements of the US and European pharmacopeia. The ELPI was preferentially used for metrology experiments using $\mathrm{NaF}$, for its ability to characterize particle size at a nanometric range, which could be helpful if the acoustic airflow decreases the aerosol particle size.

The ELPI allows the collection of nebulized particles from $7 \mathrm{~nm}$ to $10 \mu \mathrm{m}$ into 12 size fractions and operated with an air flow of $10 \mathrm{~L} \cdot \mathrm{min}^{-1}$. Prior to each measurement, the 13 ELPI impaction stages were cleaned. The corona charger was removed. The electrometer range was set at 400,000 fA, and the baseline was zeroed. The nebulizer was connected to a USP throat via a PTFE mouthpiece adaptor. The USP throat a $90^{\circ}$ bend metal pipe with uniform cross section slight contractions at the inlet and a small diffuser at the outlet. Nebulizer aerosolized $\mathrm{NaF}$ during 10 minutes, while ELPI V4.0 software recorded current vs. time data for stages 1 to 12. Afterwards, the USP throat, corona charger frame, and each stage were rinsed with 5 $\mathrm{mL}$ of deionized water into appropriate volumetric flasks. Liquids were then assayed for sodium fluoride concentration by electrochemical method indicated by the NF EN 13544-1 procedure (perfectION ${ }^{\mathrm{TM}}$ combined $\mathrm{F}^{-}$electrode SevenGo pro $^{\mathrm{TM}}$, Mettler Toledo, France). The MMAD of nebulized particles was calculated according to the standard NF EN 13544-1 using electrochemical measurements of sodium fluoride. The MMAD was interpolated from the particle size distribution curve by noting the particle size at which the line crosses the 50 
$\%$ mark. The geometric standard deviation (GSD) should only be calculated if the particle size distribution curve was reasonably straight between $10 \%$ and $90 \%$, showing that the aerosol was log-normally distributed. Where a straight line is a good fit to the data, the calculation of GSD was performed by noting the particle size $\mathrm{X}$ at which the line crosses the $84.13 \%$ mark, and the particle size $\mathrm{Y}$ at which the line crosses the $15.87 \%$ mark. Then the Geometric Standard Deviation GSD was calculated from the equation $\mathrm{X} / \mathrm{Y}^{0.5}$.

The NGI allows the collection of nebulized particles from $0.98 \mu \mathrm{m}-14.1 \mu \mathrm{m}$ into 8 size fractions and operated with an air flow of $15 \mathrm{~L} \mathrm{~min}^{-1}$. The amount of gentamicin impacted at each stage was determined by a residual gravimetric method based on weighing dry filters (Vecellio et al., 2004). The nebulizer was connected to cascade impactor via the nasal plug in order to make the measurements in the same nebulization conditions that performed with the plastinated model. The NGI was cleaned before each experiment. Known weight filters (Gelmann, Type A/E, VWR international, France) were placed into the plates of the impactor. The nebulizer equipped with its nasal plug was connected to NGI via the USP. Nasal plug was used in order to make the measurements in the same nebulization conditions that performed with the plastinated model. Solution of gentamicin $(4 \mathrm{~mL}, 80 \mathrm{mg} / \mathrm{mL}$ or $4 \mathrm{~mL}, 40$ $\mathrm{mg} / \mathrm{mL}$ ) was introduced into the nebulizer and then, vaccum pump and compressor of nebulizer were turned on. Nebulization time was limited to 10 minutes. After, filters were collected and placed at ambient temperature for drying. The USP throat was rinsed with $5 \mathrm{~mL}$ of water. Liquid was then placed on a new known weight filter, itself placed with others for drying step. 24h later all filters were again weighted. The amount of gentamicin impacted on filters at each stage in correspondence with each cut-off diameters of the NGI was calculated according to the referred method (Vecellio et al., 2004). Then, MMAD was determined since the cumulative curve mass vs. size according to European standard method NF EN 13544-1.

\subsection{Drug deposition into the maxillary sinuses}


This study assessed the deposition of an active substance on the walls of the maxillary sinuses in a plastinated nasal cast. The main objective was to examine the role of the $100 \mathrm{~Hz}$ acoustic frequency on the intrasinus deposition of nebulized drugs. In addition, we wanted to examine the impact of anatomical features (mainly ostium size) and of initial drug concentration introduced into the nebulizer on aerosol deposition. To reach these objectives the gentamicin, an aminoglycoside antibiotic, was used as a marker. We tested both concentrations of gentamicin (i.e. $40 \mathrm{mg} \cdot \mathrm{mL}^{-1}$ and $80 \mathrm{mg} \cdot \mathrm{mL}^{-1}$ ), to determine the impact of the active substance concentration on the aerosol deposition in sinuses. A constant volume of $4 \mathrm{~mL}$ of gentamicin solution was nebulized using the NL11SN jet nebulizer. Nebulizations lasted 10 minutes. Experiments were performed either with or without acoustic pressure waves at $100 \mathrm{~Hz}$, and using alternatively a $40 \mathrm{mg} \cdot \mathrm{mL}^{-1}$ or a $80 \mathrm{mg} \cdot \mathrm{mL}^{-1}$ gentamicin solution.

After the nebulization, gentamicin was collected from the maxillary sinuses by flushing with physiological serum using a syringe containing $1 \mathrm{~mL}$ for the right sinus, and $1 \mathrm{~mL}$ for the left sinus (Figure 2). Each sinus was flushed 4 times using the same physiological serum. To avoid overestimation of the amount of gentamicin deposited into the maxillary sinuses, the region close to the maxillary ostium was never flushed. Finally, the gentamicin was quantified in the liquid collected from each maxillary sinus using a fluorescence polarization immunoassay (FPIA) with TDxFLx ${ }^{\circledR}$ analyzer (Abbott Diagnostics Division, USA). The detection level of the gentamicin dosage was $0.27 \mathrm{mg} . \mathrm{L}^{-1}$. Each sample was assayed 3 times for each series of measurements and results are expressed as the mean of these 3 values. After recovery, the plastinated nasal cast was washed copiously with tap water during 10 minutes to remove all traces of residual gentamicin. Control nebulizations with physiological saline were randomly performed to verify that the gentamicin content of the flushing liquid collected was lower than the detection level (and therefore to confirm that the plastinated nasal cast washing was efficient). Globally, we have analyzed 286 collected liquid for gentamicin concentration (Table 2). 
The assay reliability is very important in this work as the main conclusions are based around the deposition of a drug that is quantified. Control nebulizations with physiological saline emphasize the absence in flushing fluid of any extracts from the cast. Thus all traces of residual gentamicin were removed after nebulization experiments. Besides, the impact of matrix effects on overall analytical performance and the potential usability of the data were determined using a spiked matrix sample. Hence, we used a representative environmental sample that has known concentration of gentamicin prior to being taken through the entire analytical process in order to evaluate bias. $1 \mathrm{~mL}$ of solution at $2.35 \mathrm{mg} . \mathrm{L}^{-1}$ of gentamicin was introduced into the maxillary sinuses to simulate an intrasinus drug deposition after nebulization. The drug recovery efficiency of the methodology used was always in the 8593\% range (i.e we measure a gentamicin concentration between 2 and $2.15 \mathrm{mg} . \mathrm{L}^{-1}$ in the flushing fluid). These results confirm a good accuracy of the methodology of drug deposition quantification into the maxillary sinuses.

\subsection{Statistical analysis}

Metrologic data obtained from cascade impactors (MMAD) and from output measurements were analyzed using non-parametric tests. Theses statistical test are adapted to small samples size and were performed with StatXact $^{\circledR}$ software (Cytel, France). Significance was established with permutation test $(\mathrm{p}<0.05)$.

The influence of using sonic mode during nebulization and the influence of gentamicin concentration on the gentamicin deposition into maxillary sinuses, data obtained from experiments performed with the plastinated head model were analyzed with t-test (on XLSTAT $^{\circledR}$ software, Addinsoft, USA). A p <0.05 was considered significantly.

\section{Results}


The clinical anatomy study by nasofiberoscopy showed that the plastinated nasal specimen was very similar to living anatomical conditions observed daily by ENT physicians. All anatomical details were well-preserved. CT scans confirmed the high preservation of the nasal airway anatomy as well as that of the mucosa of the turbinates (Figure 3). Interestingly, the plastinated specimen exhibited very dissimilar maxillary ostium morphologies. Indeed, while the right maxillary sinus ostium appeared as anatomically usual, the left maxillary ostium was doubtless abnormally short and broad. In particular, the diameter of the left maxillary sinus ostium was three times higher than that of the right maxillary sinus ostium. However, the acoustic rhinometry reasonably resolved the airways geometry of the plastinated cast. We found a perfect symmetry between the left and right nasal cavities with a minimal crosssectional area around $0.5 \mathrm{~cm}^{2}$ and a cross-sectional area higher than $1.5 \mathrm{~cm}^{2}$ from the middle meatus region (Figure 4) (Durand et al., 2011).

\subsection{Aerodynamic behaviour of the plastinated human nasal cast}

We also measured by rhinomanometry the resistance of each nasal cavity separately while the opposite nostril was occluded. From the pressure $v s$. flow curves, the unilateral airflow resistances found, for left and right nasal cavities, were perfectly similar at 0.18 Pa.s.cm ${ }^{-3}$ (i.e. $1.8 \mathrm{cmH}_{2}$ O.s. $\mathrm{L}^{-1}$ ). The bilateral airflow resistance was, logically, lower than unilateral resistances, around 0.13 Pa.s.cm ${ }^{-3}$. Finally, very original data were obtained by examining the airflow serial resistance of both the maxillary ostium and the nasal cavity. Results emphasized very disparate airflow resistances: 0.73 Pa.s. $\mathrm{cm}^{-3}$ for the left nasal cavity in serial with the left maxillary ostium, and 1.21 Pa.s.cm ${ }^{-3}$ for the right nasal cavity in serial with the right maxillary ostium. Because the uninasal airflow resistances of the left and right nasal cavities are rigorously identical $\left(0.18\right.$ Pa.s.cm $\left.{ }^{-3}\right)$, this result suggests that morphology changes of the maxillary ostium could have a huge impact on sinus ventilation. Indeed, the low airflow resistance put in evidence for the left nasal cavity in serial with the left maxillary ostium is in 
good agreement with the abnormally short and broad ostium of the left maxillary sinus as determined from CT scans (Figure 3) (Durand et al., 2011).

\subsection{Signal processing of the acoustic airflow}

The maximum acoustic pressure level generated at $100 \mathrm{~Hz}$ from the NL11SN was equal to $107 \mathrm{~dB}$ at $1 \mathrm{~cm}$ of the output pipe. The distance of measurement has been empirically chosen but it allowed relative measurements. Theoretically the signal must be a $100 \mathrm{~Hz}$ sinusoidal signal, but our results highlight that it is not exactly sinusoidal, as shown in Figure 5A. Then, a spectral analysis using the Fourier transform was performed in order to have a better understanding of the frequency components of the signal (Figure 5B). The main component of the signal is $100 \mathrm{~Hz}$ as expected, but there are three other harmonic components at 200, 300 and $400 \mathrm{~Hz}$ respectively. The fundamental amplitude is about ten times higher than the harmonics amplitudes. The harmonics are certainly due to the resonance of the pipe which behaves like a wind instrument.

\subsection{Aerosol metrology}

ELPI results using $\mathrm{NaF}$ as a marker emphasize a significant decrease of MMAD in presence of the $100 \mathrm{~Hz}$ acoustic airflow of about $35 \%(3.45 \pm 0.25 \mu \mathrm{m} v s 5.40 \pm 0.15 \mu \mathrm{m})$. NGI results using gentamicin as a marker indicate that MMAD significantly increased when the gentamicin concentration rises (Figure 6). In accordance with ELPI measurements, NGI results show also that adding the $100 \mathrm{~Hz}$ acoustic frequency during nebulization led to decrease the MMAD for a given gentamicin concentration (Figure 6).

The aerosol output measurements emphasize a huge impact of $100 \mathrm{~Hz}$ acoustic frequency. A significant decrease, about $60 \%$, of the amount of gentamicin aerosolized in presence of 100 $\mathrm{Hz}$ acoustic frequency was highlighted (Table 2). Without acoustic pressure waves 17-20\% 
of the volume of gentamicin initially introduced was nebulized, although only 7-8 \% was nebulized in presence of $100 \mathrm{~Hz}$ acoustic airflow.

\subsection{Drug deposition into the maxillary sinuses}

We sequentially studied the influence of three parameters: the $100 \mathrm{~Hz}$ acoustic airflow, the gentamicin concentration, and the maxillary ostium anatomical features. Results obtained clearly show that:

A At $80 \mathrm{mg} \cdot \mathrm{mL}^{-1}$, the drug deposition is higher in the left maxillary sinus cavity than in the right one, either in presence or in absence of acoustic airflow (Figure 7 - Table 3). As a result the endonasal anatomical features seem to play a major role on aerosol deposition.

Whatever the initial gentamicin concentration used, the drug deposition in left and right sinus cavities is higher in presence of $100 \mathrm{~Hz}$ acoustic frequency than without acoustic airflow. We emphasized that the $100 \mathrm{~Hz}$ acoustic airflow led to increase at least 2 fold the drug deposition in the maxillary sinuses for a given maxillary ostium anatomical feature (Figure 7 - Table 3).

Both in presence and in absence of acoustic airflow, an increased gentamicin concentration induced an increased drug deposition in the right as well as in the left maxillary sinuses (Figure 7 - Table 3).

\section{Discussion}

\subsection{Influence of $100 \mathrm{~Hz}$ acoustic airflow on intrasinus drug deposition}

Measurements made using the plastinated nasal cast doubtless highlight that the addition of a $100 \mathrm{~Hz}$ acoustic airflow to the gentamicin aerosol leads to a 2 to 3 fold increase drug deposition into the maxillary sinuses depending on nebulization conditions (Figure 7). Moreover, it is interesting to examine the gain of drug deposition by the $100 \mathrm{~Hz}$ acoustic airflow comparing the results with and without a $100 \mathrm{~Hz}$ acoustic frequency, all other factors 
being exactly the same (i.e. on the same sinus and gentamicin concentration). The gain in drug deposition brought about by the addition of a $100 \mathrm{~Hz}$ acoustic frequency to the aerosol production is identical, whatever the anatomic and aerodynamic endonasal features, and in particular, whatever the characteristics of the maxillary ostium (Figure 8). However, this drug deposition gain is even more important when the initial concentration of gentamicin decreases (deposition gain of about $100 \%$ at $80 \mathrm{mg} \cdot \mathrm{mL}^{-1}$ vs. a deposition gain of about $220 \%$ at 40 $\mathrm{mg} \cdot \mathrm{mL}^{-1}$ ). As a result, the gain of sinus drug deposition brought by the $100 \mathrm{~Hz}$ acoustic frequency strongly depends on the gentamicin concentration initially introduced into the nebulizer.

The metrology study indicated that the $100 \mathrm{~Hz}$ acoustic frequency significantly reduced the MMAD of the particles produced by the NL11SN and the aerosol ouput (Figure 6, Table 2). The decrease of MMAD varies from $10 \%$ to $27 \%$ depending on the initial gentamicin concentration. In the same time, the decrease of aerosol output is about $60 \%$ whatever the initial gentamicin concentration. Doubtless, the amount of gentamicin inhaled, for a same nebulization time, is less important in presence of acoustic airflow since the MMAD and the aerosol output decrease. However, as the gentamicin concentration collected into maxillary sinus is greater when nebulization is performed with a $100 \mathrm{~Hz}$ acoustic frequency, we suggest that the amount of particles penetrating into the maxillary sinus is more important in presence of a $100 \mathrm{~Hz}$ acoustic frequency.

Overall, the mechanism underlying the augmentation of drug deposition in presence of 100 $\mathrm{Hz}$ acoustic frequency was probably due to a balance between a decrease of particle size and aerosol output, and an increase of the number of the airborne particles reaching the maxillary sinuses.

But a key question remains: why does the number of airborne particles reaching the maxillary sinuses rise in presence of $100 \mathrm{~Hz}$ acoustic frequency? A first explanation could be the smaller particle size induced by the acoustic pressure waves, despite the simultaneous 
decrease of the aerosol output. But in fact, for specific experimental conditions, the rise of gentamicin concentration can balance the influence of the $100 \mathrm{~Hz}$ acoustic frequency on particle size and on aerosol output. As an example, the MMAD of particles produced by the NL11SN is almost the same when the $40 \mathrm{mg} \cdot \mathrm{mL}^{-1}$ gentamicin solution is nebulized without $100 \mathrm{~Hz}$ acoustic frequency or when the $80 \mathrm{mg} \cdot \mathrm{mL}^{-1}$ gentamicin solution is nebulized with an acoustic airflow $(2.21 \pm 0.14 \mu \mathrm{m}$ and $2.54 \pm 0.04 \mu \mathrm{m}$ respectively). Therefore, if the transport mechanism for a same particle size was similar in presence or in absence of $100 \mathrm{~Hz}$ acoustic frequency, the amount of gentamicin deposited into the maxillary sinuses when nebulized at $40 \mathrm{mg} \cdot \mathrm{mL}^{-1}$ without a $100 \mathrm{~Hz}$ acoustic frequency should be expected to be 1.5 -fold higher (because of the gentamicin concentration is twice while the aerosol output is about 3 times lower) than the amount deposited during sonic nebulization of $80 \mathrm{mg} \cdot \mathrm{mL}^{-1}$ of gentamicin. However, the drug deposition rose by a factor 6 to 8 . Consequently, for the same particle size, the presence of acoustic frequency increases by approximately a factor 5 the number of particles deposited into the maxillary sinuses independently of the acoustic frequency effect on particle size and aerosol output.

Thus, our results strongly support the existence of a specific transport mechanism of particles through ostium in the presence of $100 \mathrm{~Hz}$ acoustic frequency. Recently, Maniscalco et al. showed that an oscillating airflow produced by phonation (nasal humming) caused a large increase in the gas exchange between the nose and the paranasal sinuses (Maniscalco et al., 2006). Moreover, these authors also demonstrated that the gas ventilation between the nose and sinuses was even more important when the frequency of the acoustic airflow used was closed to the resonant frequency of the sinus cavity (Maniscalco et al., 2006-2). In fact, a cavity of air with an opening will resonate at a natural frequency when the air is excited, as the well-known principle of the Helmholtz resonator (Kinsler et al., 1962). Indeed, when air is forced into a cavity, the pressure inside increases. When the external force pushing the air into the cavity is removed, the higher-pressure air inside will flow out. However, this surge of air 
flowing out will tend to over-compensate, due to the inertia of the air in the neck, and the cavity will be left at a pressure slightly lower than outside, causing air to be drawn back in. This process repeats with the magnitude of the pressure changes decreasing each time. All things considered, we support the conclusion that the sinus cavity could be compared in a first approximation to a Helmholtz resonator. In this sense, the maxillary sinus can be comparable to a resonator system that exhibits resonant behaviour in presence of $100 \mathrm{~Hz}$ acoustic frequency. This assumption is in perfect accordance with previous work which estimated the fundamental resonant frequencies of paranasal sinuses in the range 110-350 $\mathrm{Hz}$ using the Helmholtz resonator theory (Tarhan et al., 2005).

4.2 Impact of maxillary ostium anatomical and aerodynamical characteristics on drug deposition

We demonstrated that the aerosols can penetrate into the maxillary sinuses even if we observed a differential deposition of active substance as a function of maxillary ostium anatomical features. As a matter of fact the amount of nebulized active substance collected into the sinus is higher in the left sinus of our plastinated nasal cast. This left sinus was characterized by a short and broad maxillary ostium inducing a weak airflow resistance to sinus ventilation. As a result the endonasal anatomic conditions (and the airflow resistance associated) have certainly a huge impact on drug deposition into maxillary sinuses.

Nevertheless, we also emphasized a significant drug deposition for long and quite narrow maxillary ostium (right nasal cavity of the plastinated nasal cast). The fact that a small size of the ostium allows an effective drug deposition is quite encouraging to extrapolate results to diseased subject. It is obvious that nasal airway obstruction in patients with rhinosinusitis as well as complete closure of the maxillary ostia prevent any drug deposition into the sinuses. However, we have the demonstration that aerosols can penetrate into the maxillary sinuses in the case of quite unfavorable anatomic and aerodynamic endonasal conditions. This result 
seems to be a major value of proving that nebulized drug can reach the middle meatus, which is considered to be the most common area for sinusitis disorders. In this sense our results show that the use of $100 \mathrm{~Hz}$ acoustic frequency during nebulization may provide sufficient drug delivery for a topical aerosol therapy in sinonasal disorders. Nevertheless clinical trials are required to definitively conclude on the clinically efficiency because of the nasal cast differed from in vivo mainly due to the absence of mucus or breathing with the plastinated cast.

\section{Conclusion}

The plastinated nasal cast appeared useful for in vitro characterization of drug deposition into maxillary sinuses. We demonstrated that antibiotic aerosol can penetrate into the maxillary sinuses. We also emphasized a great efficiency of the $100 \mathrm{~Hz}$ acoustic airflow to enhance drug deposition into maxillary sinuses. A significant increase (2 to 3 -fold) of intrasinus drug deposition was obtained in presence of $100 \mathrm{~Hz}$ acoustic frequency, despite the decrease of $60 \%$ of the aerosol output induced by the acoustic pressure waves. Thus, the acoustic effect allows the improvement of targeting of nebulized antibiotics to the maxillary sinuses, and even with the lower concentration of antibiotics nebulized (a great advantage to limit sideeffect and to prevent potential antiobiotic resistance). We also established that the addition of the $100 \mathrm{~Hz}$ acoustic frequency reduces the aerodynamic particle size (MMAD). Moreover, the gain of drug deposition observed in presence of acoustic airflow was independent of the anatomical and aerodynamical characteristics of the maxillary ostium. These results suggest that a specific transport mechanism of airborne particle occurs during an acoustic airflow nebulization. The mechanisms seem to induce a significant rise of the number of particles penetrating into the maxillary sinus independently of changes on particle size and aerosol output. The comparison of the sinus cavity to a Helmholtz resonator could, at least partially, explain the phenomenon observed. Finally, we demonstrated that the gain of drug deposition 
observed with $100 \mathrm{~Hz}$ acoustic frequency depends on the gentamicin concentration initially introduced into the nebulizer. Therefore, this result indicates that specific drug and/or specific dosages should be selected to fully benefit from the deposition enhancement brought by the $100 \mathrm{~Hz}$ acoustic airflow nebulizer.

\section{Conflict of interest}

S. Le Guellec is an employee of Diffusion Technique Française (DTF Medical, Saint Etienne, France).

\section{References}

Cakmak, O., Celik, H., Cankurtaran, M., Buyuklu, F., Ozgirgin, N., Ozluoglu, L.N., 2003. Effects of paranasal sinus ostia and volume on acoustic rhinometry measurements: a model study. J Appl Physiol. 94:1527-1535

Croce, C., Fodil, R., Durand, M., Sbirlea-apiou, G., Caillibotte, G., Papon, J.F., Blondeau, J.R., Coste, A., Isabey, D., Louis, B., 2006. In vitro experiments and numerical simulations of airflow in realistic nasal airway geometry. Ann Biomed Eng. 34:997-1007.

Durand, M., Pourchez, J., Louis, B., Pouget, J.F., Isabey, D., Coste, A., Prades, J.M., Rusch, P., Cottier, M., 2011. Plastinated nasal model: a new concept of anatomically realistic cast. Rhinology. 49(1), 30-36.

Durand, M., Rusch, P., Granjon, D., Chantrel, G., Prades, J.M., Dubois, F., Esteve, D., Pouget, J.F., Martin, C., 2001. Preliminary study of the deposition of aerosol in the maxillary sinuses using a plastinated model. J Aerosol Med. 14:83-93.

Fokkens, W.J., Lund, V.J., Mullol, J. et al., 2007. European Position Paper on Rhinosinusitis and Nasal Polyps. Rhinology. 45; suppl. 20: 1-139.

Guillerm, R., Badre, R., Flottes, L., Riu R., Rey, A., 1959. A new method of aerosol penetration into the sinuses (in french). Presse Med. 67:1097-1098. 
Kinsler, L.E., Frey, A.R., 1962. Fundamentals of acoustics ( $2^{\text {nd }}$ ed.). New York: Wiley. Hilton, C., Wiedmann, T., St. Martin, M., Humphrey, B., Schleiffarth, R., Rimell, F., 2008. Differential deposition of aerosols in the maxillary sinus of human cadavers by particle size. Am J Rinol. 22:395-398.

Hyo, N., Takano, H., Hyo, Y., 1989. Particle deposition efficiency of therapeutic aerosols in the human maxillary sinus. Rhinology. 27:17-26.

Maniscalco, M., Sofia, M., Weitzberg, E., Lundberg, J.O., 2006. Sounding airflow enhances aerosol delivery into the paranasal sinuses. Eur J Clin Invest. 36(7):509-513.

Maniscalco, M., 2006-2. Humming nitric oxide and paranasal sinus ventilation. In:

Thesis. Karolinska University Press, Stockholm, Sweden.

Marple, V.A.; Olson, B.A.; Santhanakrishnan, K.; Roberts, D.L.; Mitchell, J.P.; Hudson-Curtis, B.L., 2004. Next generation pharmaceutical impactor: a new impactor for pharmaceutical inhaler testing. Part III. extension of archival calibration to $15 \mathrm{~L} / \mathrm{min}$. J Aerosol Med.;17(4):335-43.

Moeller, W., Schuschnig, U., Meyer, G., Mentzel, H., Keller, M., 2008. Ventilation and drug delivry to the paranasal sinuses: studies in a nasal cast using pulsating airflow. Rhinology. 46:213-220.

Moeller, W., Schuschnig, U., Saba, G.K., Meyer, G., Junge-Hulsing, B., Keller, M., Haussinger, K., 2010. Pulsating aerosols for drug delivry to the sinuses in healthy volunteers. Otolaryngol Head Neck Surg. 142:382-388.

Saijo, R., Majima, Y., Hyo, N., Takano, H., 2004. Particle deposition efficiency of therapeutic aerosols in the nose and paranasal sinuses after transnasal sinus surgery. Am $\mathbf{J}$ Rinol. 18:1-7.

Schreck, S., Sullivan, K.J., Ho, C.M., Chang, H.K., 1993. Correlation between flow resistance and geometry in a model of the human nose. J Appl Physiol. 75:1767-1775. 
Kelly, J.T., Prasad, A.K., Wexler, A.S., 2000. Detailed flow patterns in the nasal cavity.

J. Appl. Physiol. 51:5-19.

Tarhan, E., Coskun, M., Cakman, O., Celik, H., Cankurtaran, M., 2005. Acoustic rhinometry in humans: accurancy of nasal passage area estimates, and ability to quantify paranasal sinus volume and ostium size. J. Appl Physiol. 99:616-623.

Vaughan, W.C., Carvalho, G., 2002. Use of nebulized antibiotics for acute infections in chronic sinusitis. Otolaryngol Head Neck Surg. 126:558-568.

Vecellio, L., De Gersem, R., Le Guellec, S., Reychler, G., Pitance, L, . Le Pennec, D., Diot, P., Chantrel, G., Bonfils, P., Jamar, F., 2011. Deposition of aerosols delivered by nasal route with jet and mesh nebulizers, International Journal of Pharmaceutics. 407:87-94.

Vecellio, L., Grimbert, D., Bordenave, J., Benoit, G., Furet, Y., Fauroux, D., Boissinot, E., de Monte, M., Lemarie, E., Diot, P., 2004. Residual gravimetric method to measure nebulizer output. J Aerosol Med Deposit Cleareance Effects Lung. 17:63-71.

von Hagens, G., 1979. Impregnation of soft biological specimens with thermosetting resins and elastomer. Anat. Rec. 194:247-255. 


\section{Impact of Acoustic Airflow Nebulization on Intrasinus Drug Deposition of a Human Plastinated Nasal Cast: New Insights into the Mechanisms involved}

Marc DURAND ${ }^{1,2,3}$, Jérémie POURCHEZ ${ }^{2,3,4 *}$, Gérald AUBERT ${ }^{5,}$, Sandrine LE GUELLEC ${ }_{6,7}$, Laurent NAVARRO ${ }^{3,4}$, Valérie FOREST ${ }_{2,3,5,8,9}^{2,3,4}$, Philippe RUSCH $^{2,3,5,8,9}$, Michèle COTTIER

${ }^{1}$ Centre Hospitalier Emile Roux, F-43012, Le Puy en Velay, France

2 LINA, Laboratoire Interdisciplinaire d'étude des Nanoparticules Aérosolisées, EA 4624, F42023, Saint-Etienne, France

${ }^{3}$ SFR IFRESIS, F-42023, Saint-Etienne, France

${ }^{4}$ Ecole Nationale Supérieure des Mines de Saint-Etienne, Centre Ingénierie et Santé, F42023, Saint-Etienne, France

${ }^{5}$ CHU de Saint-Etienne, F-42055, Saint-Etienne, France

${ }^{6}$ DTF-Aerodrug, Faculté de médecine, F-37032, Tours, France

${ }^{7}$ INSERM-U618, Faculté de Médecine, F-37032, Tours, France

${ }^{8}$ Université Jean Monnet, Faculté de Médecine, F-42023, Saint-Etienne, France

${ }^{9}$ Université de Lyon, F-42023, Saint-Etienne, France

* Corresponding author: Tel: (+33) 4774201 80; Fax: (+33) 4774996 94;

E-mail address: pourchez@emse.fr 


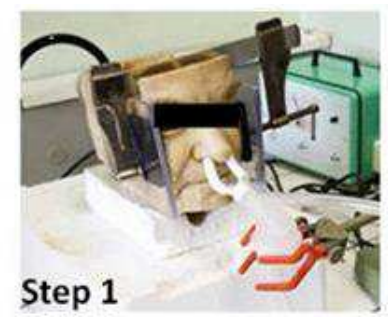

Nebulization of gentamicin solution during 10 minutes

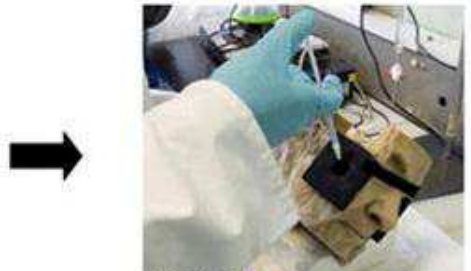

Step 2

Collection of Gentamicin from the maxillary sinuses by flushing the cavity with physiological serum

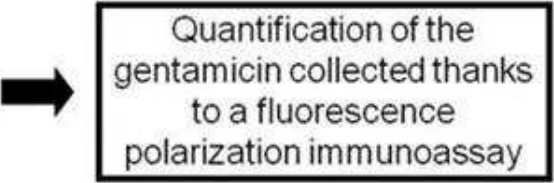

Step 3

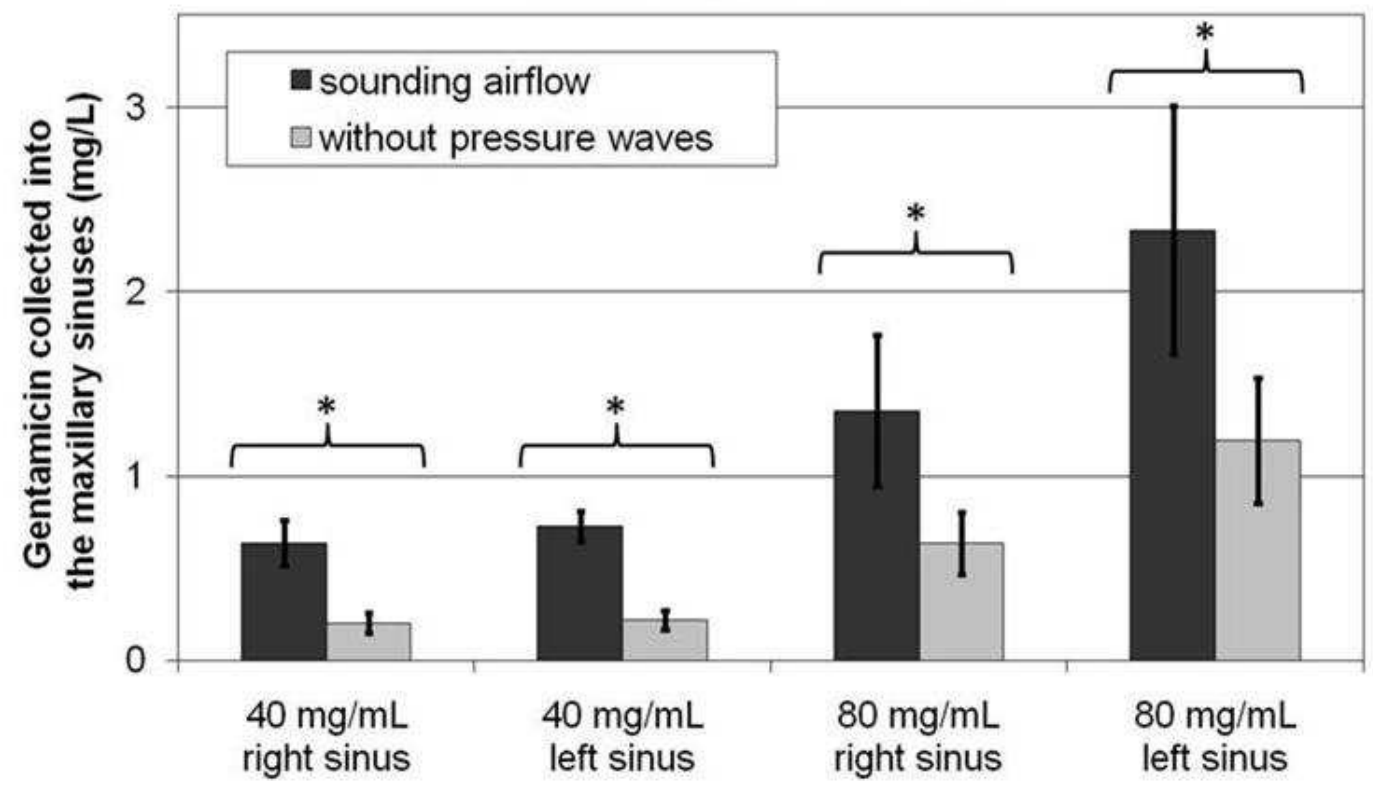




\section{Impact of Acoustic Airflow Nebulization on Intrasinus Drug Deposition of a Human Plastinated Nasal Cast: New Insights into the Mechanisms involved}

Marc DURAND ${ }^{1,2,3}$, Jérémie POURCHEZ ${ }^{2,3,4 *}$, Gérald AUBERT ${ }^{5,}$, Sandrine LE GUELLEC ${ }_{6,7}$, Laurent NAVARRO ${ }^{3,4}$, Valérie FOREST ${ }_{2,3,5,8,9}^{2,3,4}$, Philippe RUSCH $^{2,3,5,8,9}$, Michèle COTTIER

${ }^{1}$ Centre Hospitalier Emile Roux, F-43012, Le Puy en Velay, France

2 LINA, Laboratoire Interdisciplinaire d'étude des Nanoparticules Aérosolisées, EA 4624, F42023, Saint-Etienne, France

${ }^{3}$ SFR IFRESIS, F-42023, Saint-Etienne, France

${ }^{4}$ Ecole Nationale Supérieure des Mines de Saint-Etienne, Centre Ingénierie et Santé, F42023, Saint-Etienne, France

${ }^{5}$ CHU de Saint-Etienne, F-42055, Saint-Etienne, France

${ }^{6}$ DTF-Aerodrug, Faculté de médecine, F-37032, Tours, France

${ }^{7}$ INSERM-U618, Faculté de Médecine, F-37032, Tours, France

${ }^{8}$ Université Jean Monnet, Faculté de Médecine, F-42023, Saint-Etienne, France

${ }^{9}$ Université de Lyon, F-42023, Saint-Etienne, France

* Corresponding author: Tel: (+33) 4774201 80; Fax: (+33) 4774996 94;

E-mail address: pourchez@emse.fr 
Figure 1

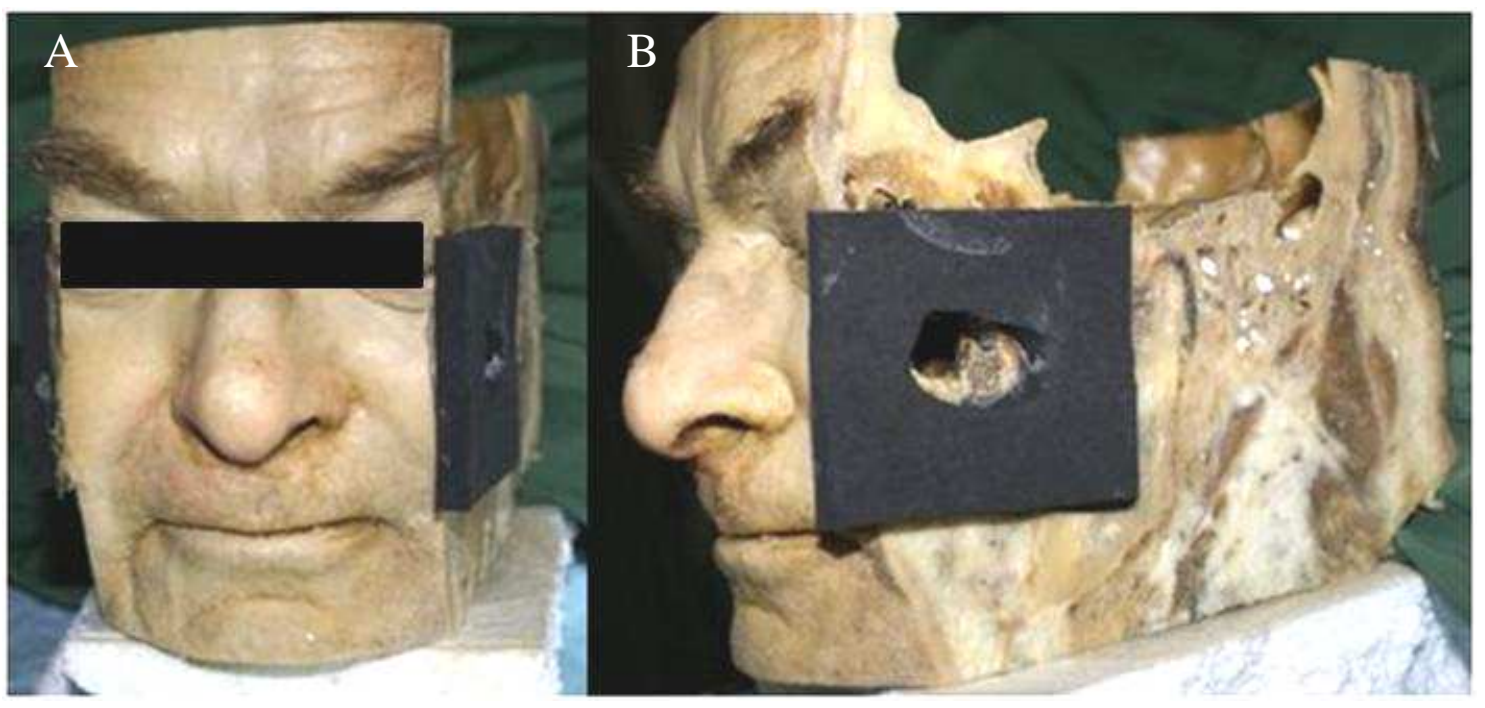

3 
$4 \quad$ Figure 1: Plastinated head model elaborated by a specific plastination procedure and used as a 5 nasal cast to assess the deposition of drug into the maxillary sinuses. (A) represents the 6 anterior view and (B) represents the lateral view showing the exterior free access to the left 7 maxillary sinuses.

8 


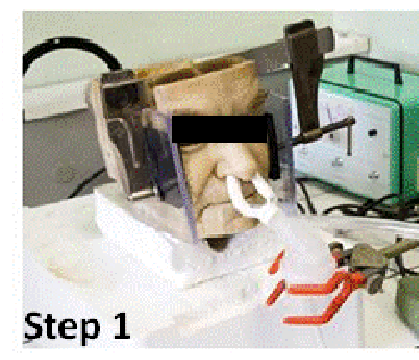

Nebulization of gentamicin solution during 10 minutes

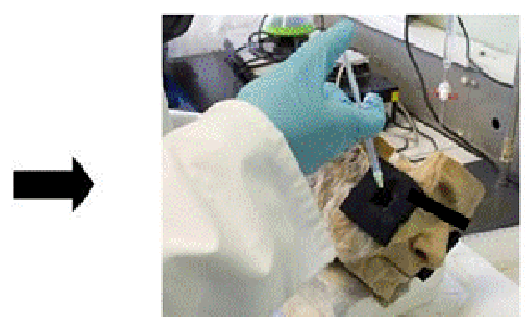

Step 2

Collection of Gentamicin from the maxillary sinuses by flushing the cavity with physiological serum
Quantification of the gentamicin collected thanks to a fluorescence polarization immunoassay 
Figure 2: Overall description of the drug deposition assessment procedure on the plastinated 16 nasal cast. 
Figure 3
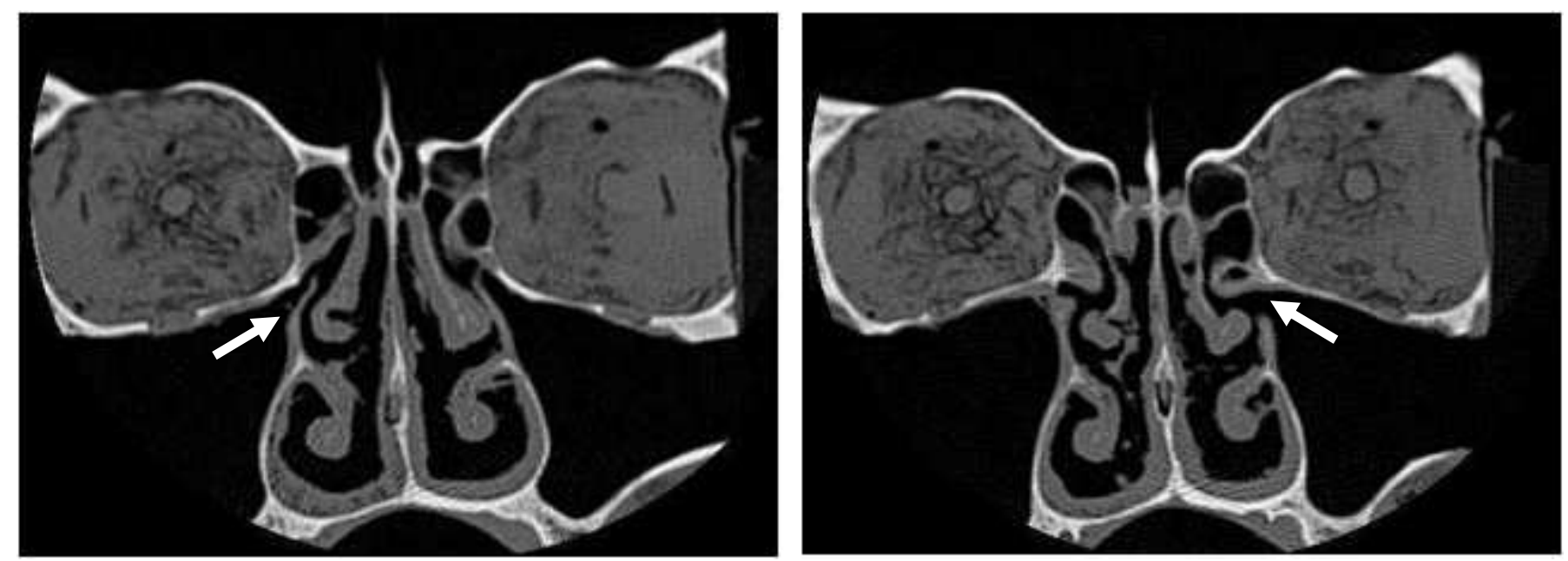

20 
Figure 3: CT scans performed on the plastinated specimen. Observation of the high preservation of the mucosa and of the different morphology of the maxillary ostia on both side (white arrows indicate maxillary ostia). 
Figure 4

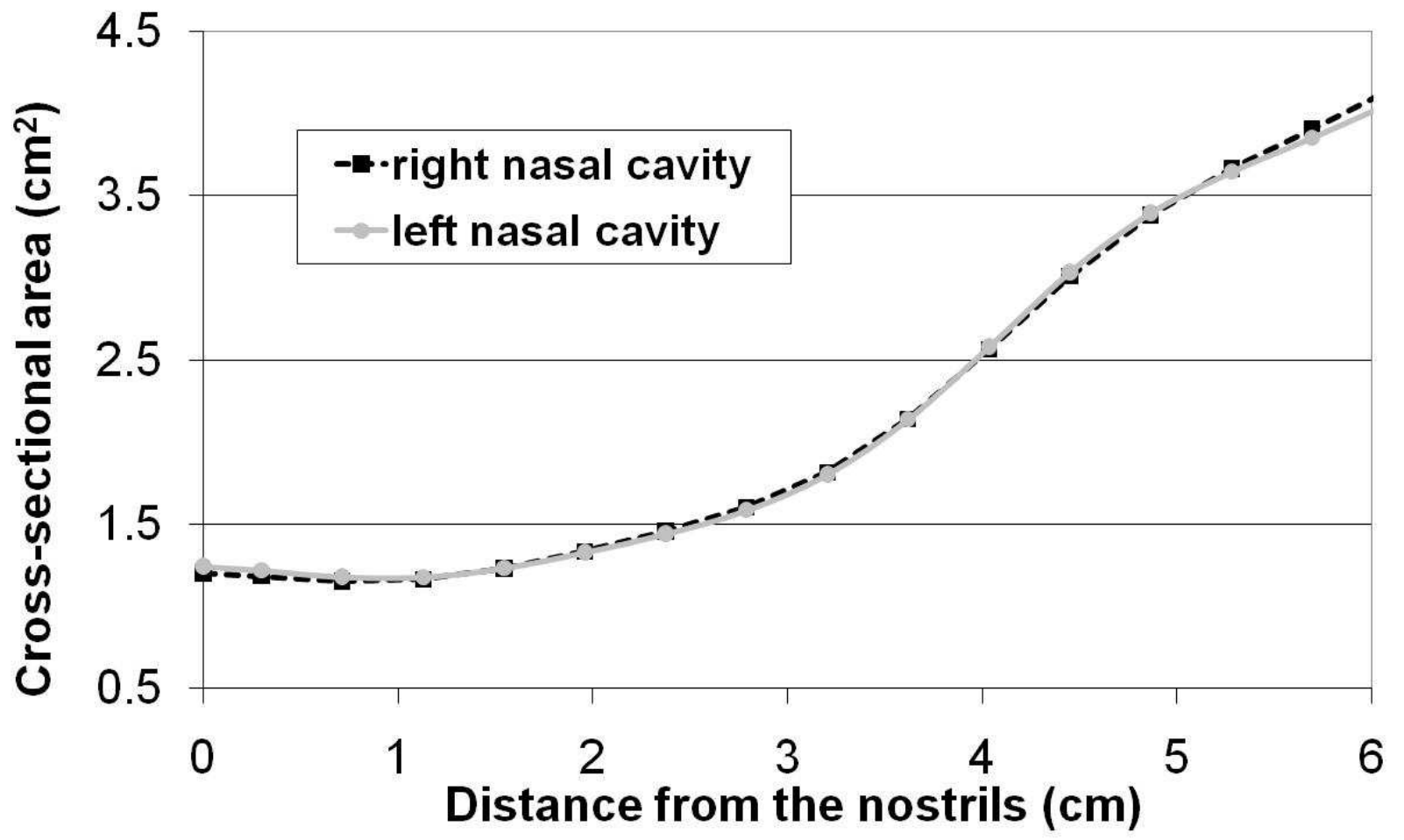


Figure 4: Acoustic rhinometry results obtained on the plastinated nasal cast.

31 

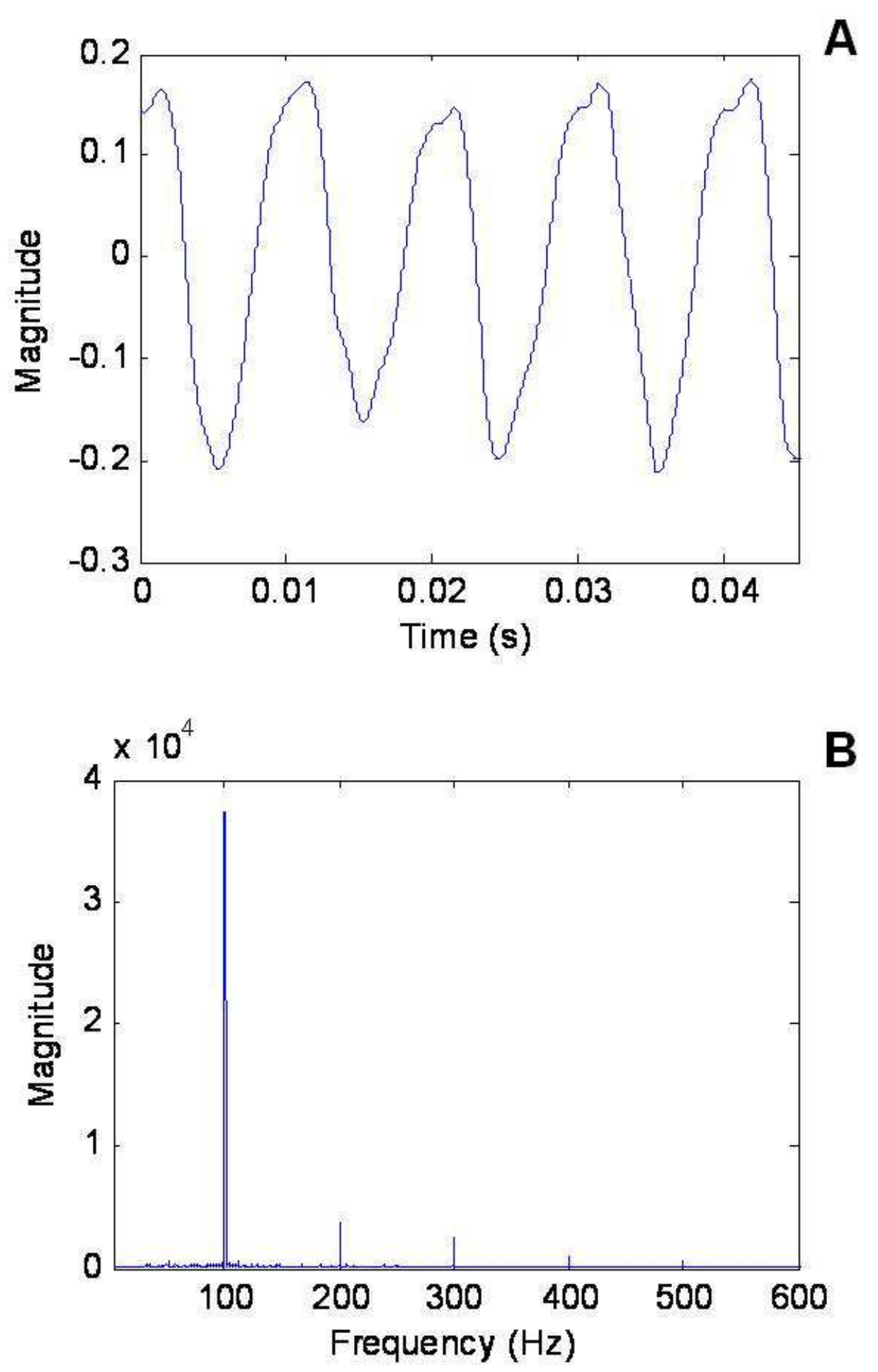
Figure 5: Signal processing of the $100 \mathrm{~Hz}$ sound added to the aerosol during its production by the NL11SN nebulizer / $\mathrm{AOLH}^{\circledR}$ compressor / $\mathrm{AS}^{\circledR}$ sonic generator: shape of the acoustic signal (A) and spectral analysis using the Fourier transform (B). 
Figure 6

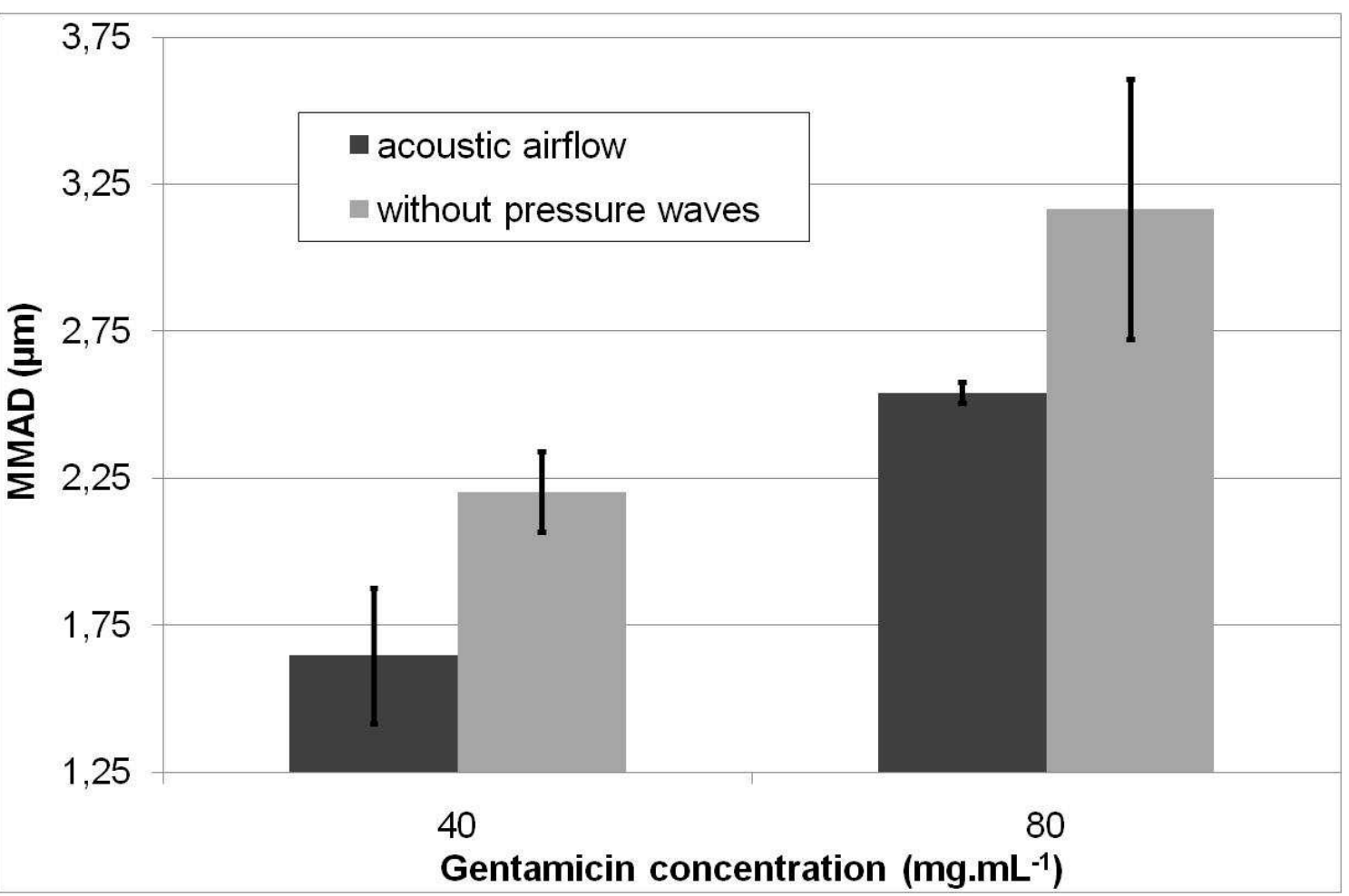


Figure 6: Impact of nebulization conditions $(100 \mathrm{~Hz}$ acoustic airflow and gentamicin concentration) on the metrology of airborne particle measured using the NGI impactor

(Permutation test: MMAD without sound pressure waves vs. MMAD with acoustic airflow: $\mathrm{p}$ $=0.0007 ; \mathrm{MMAD}$ at $40 \mathrm{mg} \cdot \mathrm{mL}^{-1}$ vs. MMAD at $\left.80 \mathrm{mg} \cdot \mathrm{mL}^{-1}: \mathrm{p}=0.005\right)$. 
Figure 7

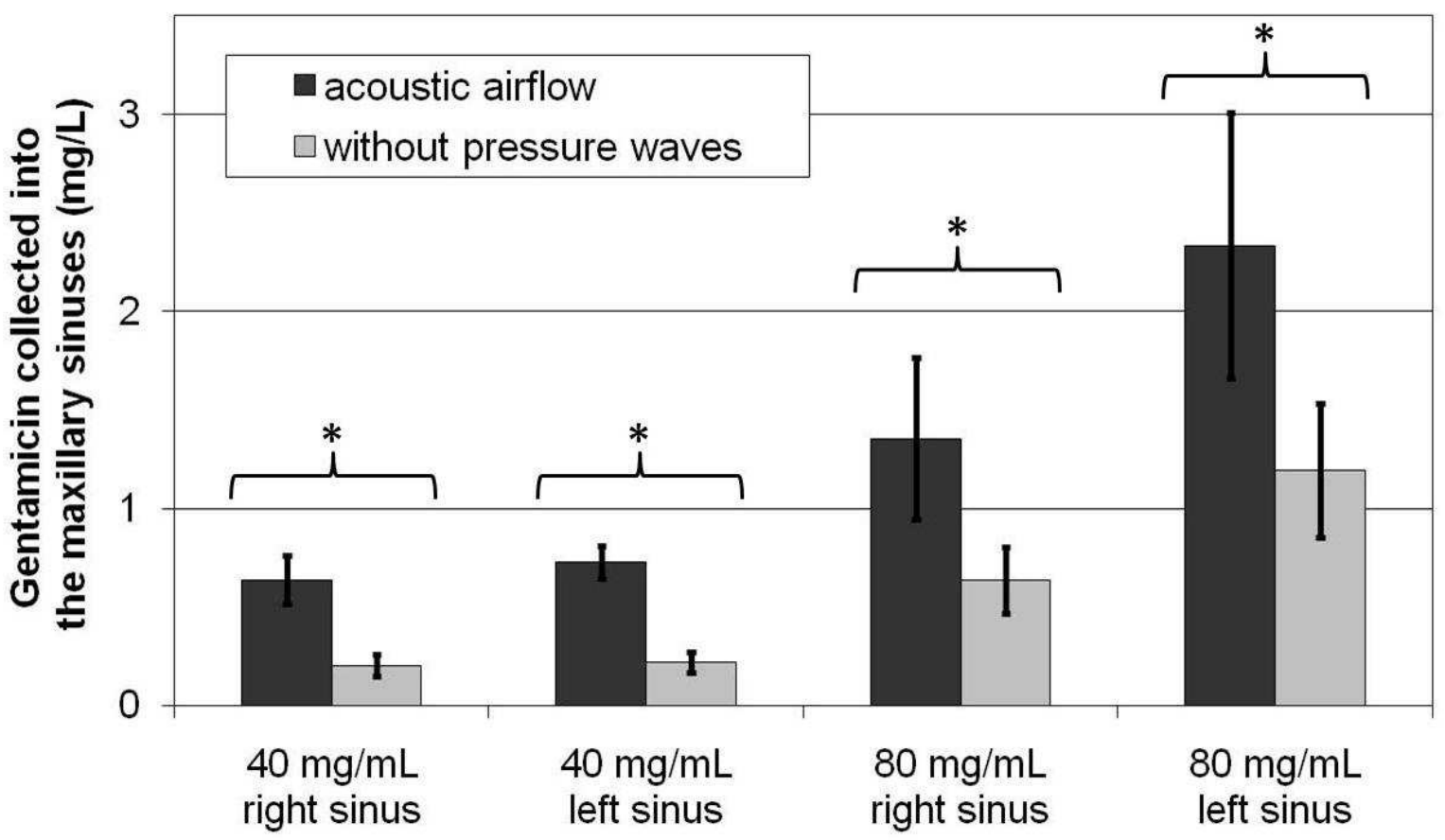


Figure 7: Influence of a $100 \mathrm{~Hz}$ acoustic airflow on the amount of nebulized gentamicin collected into the maxillary sinuses of the plastinated nasal cast $\left(^{*}:\right.$ comparisons are statistically significant). 


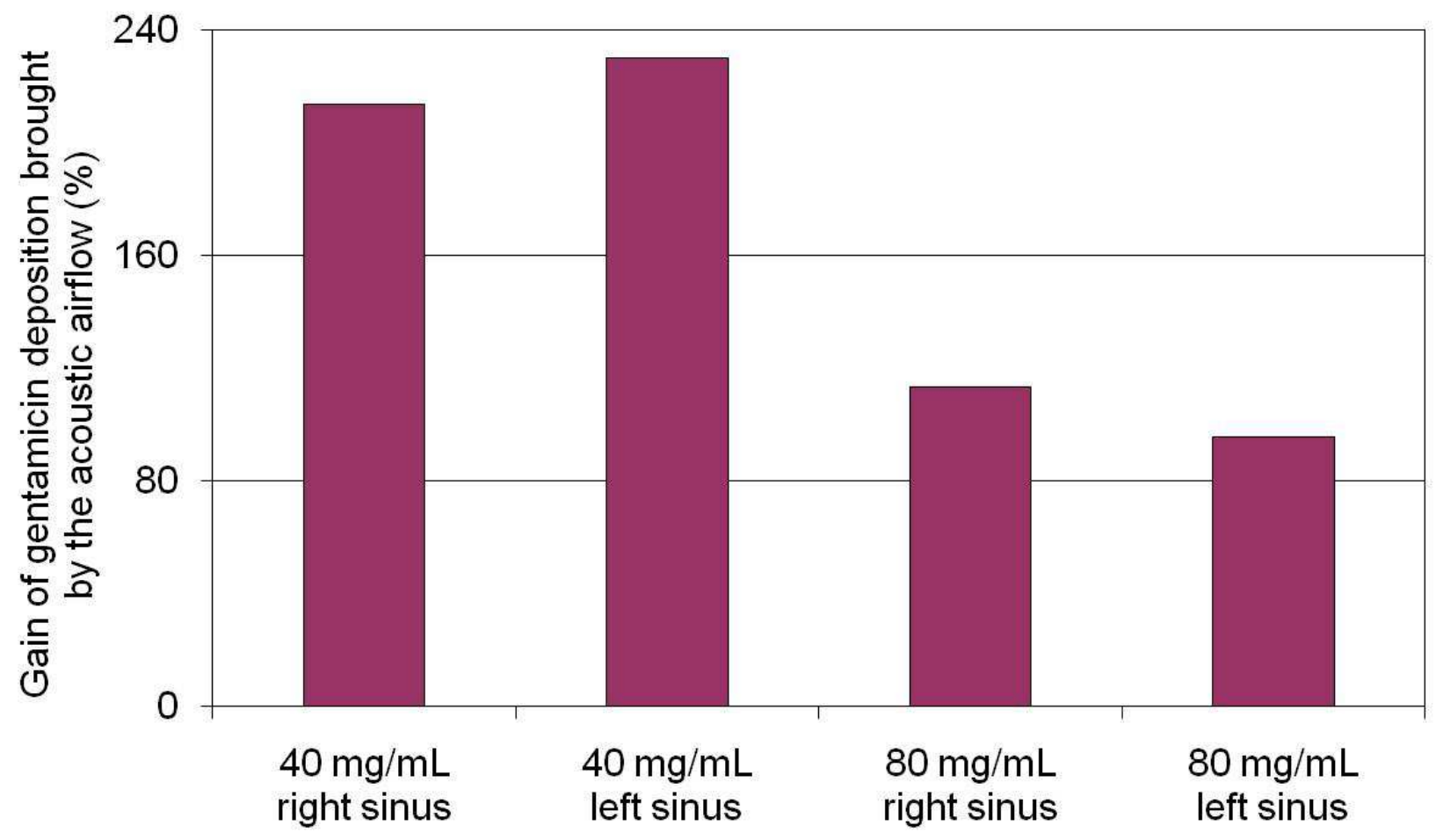


62

68

69 0 2

Figure 8: Influence of the endonasal anatomical features and the initial gentamicin concentration introduced into the nebulizer on the sinus deposition gain brought by the 100 $\mathrm{Hz}$ acoustic airflow (in comparison with experiments without sound pressure waves).

67 


\section{Impact of Acoustic Airflow Nebulization on Intrasinus Drug Deposition of a Human Plastinated Nasal Cast: New Insights into the Mechanisms involved}

Marc DURAND ${ }^{1,2,3}$, Jérémie POURCHEZ ${ }^{2,3,4 *}$, Gérald AUBERT ${ }^{5,}$, Sandrine LE GUELLEC ${ }_{6,7}$, Laurent NAVARRO ${ }^{3,4}$, Valérie FOREST ${ }_{2,3,5,8,9}^{2,3,4}$, Philippe RUSCH $^{2,3,5,8,9}$, Michèle COTTIER

${ }^{1}$ Centre Hospitalier Emile Roux, F-43012, Le Puy en Velay, France

2 LINA, Laboratoire Interdisciplinaire d'étude des Nanoparticules Aérosolisées, EA 4624, F42023, Saint-Etienne, France

${ }^{3}$ SFR IFRESIS, F-42023, Saint-Etienne, France

${ }^{4}$ Ecole Nationale Supérieure des Mines de Saint-Etienne, Centre Ingénierie et Santé, F42023, Saint-Etienne, France

${ }^{5}$ CHU de Saint-Etienne, F-42055, Saint-Etienne, France

${ }^{6}$ DTF-Aerodrug, Faculté de médecine, F-37032, Tours, France

${ }^{7}$ INSERM-U618, Faculté de Médecine, F-37032, Tours, France

${ }^{8}$ Université Jean Monnet, Faculté de Médecine, F-42023, Saint-Etienne, France

${ }^{9}$ Université de Lyon, F-42023, Saint-Etienne, France

* Corresponding author: Tel: (+33) 4774201 80; Fax: (+33) 4774996 94;

E-mail address: pourchez@emse.fr 
Table 1

\begin{tabular}{|c|c|c|c|c|c|}
\hline \multicolumn{2}{|c|}{ Nebulization conditions } & \multicolumn{2}{c|}{ Metrology experiments } \\
\hline $\begin{array}{c}\text { Type of } \\
\text { marker }\end{array}$ & $\begin{array}{c}\text { Wolume and }(w) \\
\text { concentration } \\
\text { or without } \\
\text { (wo) } \\
\text { acoustic } \\
\text { airflow }\end{array}$ & ELPI & NGI & Output \\
\hline $\mathrm{NaF}$ & $\begin{array}{c}4 \mathrm{~mL} \\
2.5 \% \mathrm{wt}\end{array}$ & $\mathrm{w}$ & $\mathrm{n}=3$ & & \\
\hline $\mathrm{NaF}$ & $\begin{array}{c}4 \mathrm{~mL} \\
2.5 \% \mathrm{wt}\end{array}$ & wo & $\mathrm{n}=3$ & & \\
\hline Gentamicin & $\begin{array}{c}4 \mathrm{~mL} \\
40 \mathrm{mg} \cdot \mathrm{mL}^{-1}\end{array}$ & w & & $\mathrm{n}=3$ & $\mathrm{n}=3$ \\
\hline Gentamicin & $\begin{array}{c}4 \mathrm{~mL} \\
40 \mathrm{mg} \cdot \mathrm{mL}^{-1}\end{array}$ & wo & & $\mathrm{n}=3$ & $\mathrm{n}=3$ \\
\hline Gentamicin & $\begin{array}{c}4 \mathrm{~mL} \\
80 \mathrm{mg} \cdot \mathrm{mL}^{-1}\end{array}$ & w & & $\mathrm{n}=3$ & $\mathrm{n}=3$ \\
\hline Gentamicin & $\begin{array}{c}4 \mathrm{~mL} \\
80 \mathrm{mg} \cdot \mathrm{mL}^{-1}\end{array}$ & wo & & $\mathrm{n}=3$ & $\mathrm{n}=3$ \\
\hline
\end{tabular}


Table 1: Design of the metrology experiments conducted during the study. 
Table 2

\begin{tabular}{|c|c|c|c|}
\hline $\begin{array}{c}\text { Nebulization } \\
\text { conditions }\end{array}$ & Type of nebulization & $\begin{array}{c}\text { Number of } \\
\text { experiments } \\
\text { (gentamicin dosage) }\end{array}$ & $\begin{array}{c}\text { Aerosol output } \\
\text { results }\end{array}$ \\
\hline $\begin{array}{c}\text { Control nebulization } \\
\text { with physiological } \\
\text { saline solution } \\
\text { (4 mL without } \\
\text { gentamicin) }\end{array}$ & $\begin{array}{c}10 \text { minutes } \\
\text { nebulization }\end{array}$ & 66 & - \\
\hline $\begin{array}{c}\text { Gentamicin solution } \\
\left(4 \mathrm{~mL} \text { at } 40 \mathrm{mg} \cdot \mathrm{mL}^{-1}\right)\end{array}$ & $\begin{array}{c}10 \text { minutes } \\
\text { nebulization } \\
\text { "classic" operating } \\
\text { mode }\end{array}$ & 62 & $0.83 \pm 0.05 \mathrm{~mL}$ \\
\hline $\begin{array}{c}\text { Gentamicin solution } \\
\left(4 \mathrm{~mL} \text { at } 40 \mathrm{mg} \cdot \mathrm{mL}^{-1}\right)\end{array}$ & $\begin{array}{c}10 \text { minutes } \\
\text { nebulization } \\
\text { "sonic" operating } \\
\text { mode }\end{array}$ & 54 & $0.32 \pm 0.02 \mathrm{~mL}$ \\
\hline $\begin{array}{c}\text { Gentamicin solution } \\
\left(4 \mathrm{~mL} \text { at } 80 \mathrm{mg} \cdot \mathrm{mL}^{-1}\right)\end{array}$ & $\begin{array}{c}10 \text { minutes } \\
\text { "classic" operating } \\
\text { mode }\end{array}$ & 68 & $0.68 \pm 0.04 \mathrm{~mL}$ \\
\hline $\begin{array}{c}10 \text { minutes } \\
\text { Gentamicin solution }\end{array}$ & $\begin{array}{c}\text { nebulization } \\
\text { "sonic" operating } \\
\left.\text { mode } 80 \mathrm{mg} \cdot \mathrm{mL}^{-1}\right)\end{array}$ & 36 & $0.30 \pm 0.02 \mathrm{~mL}$ \\
\hline
\end{tabular}


11 Table 2: Design of the drug deposition experiments conducted on the plastinated nasal cast

12 and results of the aerosol output measurements. "sonic" operating mode corresponds to

13 nebulization with $100 \mathrm{~Hz}$ acoustic airflow. "classic" operating mode corresponds to

14 nebulization without acoustic pressure waves.

15 
Table 3

\begin{tabular}{|c|c|c|c|c|c|c|c|}
\hline & $\begin{array}{l}40 \mathrm{mg} / \mathrm{mL} \\
\text { left sinus }\end{array}$ & $\begin{array}{l}40 \mathrm{mg} / \mathrm{mL} \\
\text { right sinus }\end{array}$ & $\begin{array}{l}80 \mathrm{mg} / \mathrm{mL} \\
\text { left sinus }\end{array}$ & $\begin{array}{l}80 \mathrm{mg} / \mathrm{mL} \\
\text { right sinus }\end{array}$ & $\begin{array}{c}40 \mathrm{mg} / \mathrm{mL} \\
\text { left sinus } \\
\text { acoustic } \\
\text { airflow }\end{array}$ & $\begin{array}{l}40 \mathrm{mg} / \mathrm{mL} \\
\text { right sinus } \\
\text { acoustic } \\
\text { airflow }\end{array}$ & $\begin{array}{c}80 \mathrm{mg} / \mathrm{mL} \\
\text { left sinus } \\
\text { acoustic } \\
\text { airflow }\end{array}$ \\
\hline $40 \mathrm{mg} / \mathrm{mL}$ - right sinus & $p=0.679$ & & & & & & \\
\hline $80 \mathrm{mg} / \mathrm{mL}$ - left sinus & $\begin{array}{c}* \\
\mathbf{p}<0.0001\end{array}$ & & & & & & \\
\hline $80 \mathrm{mg} / \mathrm{mL}$ - right sinus & & $\begin{array}{c}* \\
\mathrm{p}<0.0001\end{array}$ & $\begin{array}{c}* \\
\mathbf{p}=0.005\end{array}$ & & & & \\
\hline $\begin{array}{c}40 \mathrm{mg} / \mathrm{mL} \text { - left sinus } \\
\text { acoustic airflow }\end{array}$ & $\begin{array}{c}* \\
\mathbf{p}<0.0001\end{array}$ & & & & & & \\
\hline $\begin{array}{l}40 \mathrm{mg} / \mathrm{mL} \text { - right sinus } \\
\text { acoustic airflow }\end{array}$ & & $\begin{array}{c}* \\
\mathbf{p}<0.0001\end{array}$ & & & $p=0.242$ & & \\
\hline $\begin{array}{l}80 \mathrm{mg} / \mathrm{mL} \text { - left sinus } \\
\text { acoustic airflow }\end{array}$ & & & $\begin{array}{c}* \\
\mathbf{p}=\mathbf{0 . 0 0 0 5}\end{array}$ & & $\begin{array}{c}* \\
\mathbf{p}<0.0001\end{array}$ & & \\
\hline $\begin{array}{c}80 \mathrm{mg} / \mathrm{mL} \text { - right sinus } \\
\text { acoustic airflow }\end{array}$ & & & & $\begin{array}{c}* \\
\mathbf{p}=\mathbf{0 . 0 0 2}\end{array}$ & & $\begin{array}{c}* \\
\mathbf{p}=\mathbf{0 . 0 0 1}\end{array}$ & $\begin{array}{c}* \\
p=0.019\end{array}$ \\
\hline
\end{tabular}

17 
20 Table 3: Statistical analysis of gentamicin aerosol deposition into the maxillary sinuses of the 21 plastinated nasal cast. Light grey: impact of a $100 \mathrm{~Hz}$ acoustic airflow; grey: impact of the initial gentamicin concentration introduced into the nebulizer, dark grey: impact of endonasal anatomical features (disparate size and morphology of left and right ostia). 